\title{
Las intarsias de la sillería del coro de Plasencia: influencia italiana temprana en el núcleo artístico toledano
}

\author{
Dorothée HeIM \\ Staatlichen Museen zu Berlin \\ dorothee_heim@yahoo.de
}

\begin{abstract}
RESUMEN
En la obra de Rodrigo Alemán, uno de los entalladores más importantes del núcleo toledano de escultura tardogótica, se pueden encontrar elementos claramente renacentistas y anteriores a la estancia de Andrea Sansovino en 1500 en Toledo, revulsivo que aceleró la introducción del Renacimiento. La sillería coral de Plasencia (1497-1508) presenta, en los sitiales altos, un conjunto de tableros y respaldos intarsiados, donde se representan figuras de santos y los retratos de los Reyes Católicos, que fueron realizados al mismo tiempo que el resto de la decoración tallada. Tras concluir que no pueden deberse a una evolución de los trabajos de este tipo que existían anteriormente en España, se comparan las intarsias placentinas con otras italianas contemporáneas, estableciéndose que, por sus características técnicas y los ornamentos utilizados, especialmente los grutescos, guardan relación con las realizadas en Florencia y sus zonas de influencia artística, especialmente Perugia y Urbino. El pintor Pedro Berruguete, activo en esta última ciudad, pudo haber sido el inspirador de la inclusión de las intarsias en la sillería tardogótica de Plasencia.
\end{abstract}

Palabras clave: Rodrigo Alemán, Pedro Berruguete, sillería coral, Plasencia, intarsia, Florencia.

\begin{abstract}
Among the Works of Rodrigo Alemán, one of the most important sculptors in the Toletian late gothic sculpture group, it is possible to identify some Renaissance elements which were added prior to the deep changes arising after the stay of Andrea Sansovino in Toledo in 1500. The choir stalls in Plasencia (1497-1508) comprise intarsia panels decorated with figures representing saints and the portraits of the Catholic King and Queen. These panels were made simultaneously to the stalls. After concluding that these decorative intarsia panels cannot be the result of an evolution of the models made in Spain until that moment, it is established, based on comparisons with intarsia decorations in Italy, that they show remarkable similarities, both technical and related to the ornaments used, especially the grotesques, with those made in the area of artistic influence of Florence, in particular Perugia and Urbino. It is further suggested that Pedro Berruguete, who was active in the latter city, could be the link to explain the introduction of Italian intarsia panels in the choir stalls in Plasencia.
\end{abstract}

Keywords: Rodrigo Alemán, Pedro Berruguete, choir stalls, Plasencia, intarsia, Florence.

\section{Todo empieza con Sansovino. ¿O quizás no?}

En la transición desde la tradición tardogótica a las formas renacentistas, hay un momento decisivo, en lo que a la escultura toledana se refiere, que coincide con la estancia en Toledo de Andrea Sansovino en julio de 1500. El escultor florentino, llegado a la Península Ibérica para atender encargos del rey de Portugal, labró 
durante esta visita dos figuras destinadas al retablo de la capilla mayor de la catedral primada, las cuales eran en realidad dos muestras para que el cabildo pudiera valorar la capacidad del artista. La concepción de estas figuras es absolutamente innovadora en el panorama artístico de la ciudad. Estas dos esculturas actuaron con seguridad como revulsivo dentro del grupo de entalladores más destacados de entre aquellos activos en la ciudad, quienes empezaron a partir de entonces a abandonar los cánones tardogóticos y a recoger las nuevas formas renacentistas ${ }^{1}$.

La experiencia, sin embargo, nos enseña que un cambio de tal calado necesita, en primer lugar y sobre todo, tiempo. Varios factores han de combinarse para que se produzca una alteración tan profunda del paradigma artístico. La influencia de un artista italiano, aún siendo alguien de gran fama, solamente podría provocar un efecto tan radical y permanente si encontrara un terreno abonado y preparado. Tenía que haber en Toledo un germen, un grupo de artistas cuya sensibilidad y curiosidad les convirtiera en receptores de estos impulsos renovadores. De hecho, son varios los factores que convergen en Toledo por estos años y que facilitaron una implantación relativamente rápida de los nuevos ideales artísticos.

En primer lugar, debemos referirnos a la paulatina adopción del pensamiento humanista por las élites intelectual y política castellanas, fenómeno que ya se inicia durante la primera mitad del siglo XV. Entre las figuras más destacadas que muestran interés por las nuevas ideas se encuentra el cardenal Pedro González de Mendoza (1428-1495), lector interesado y traductor en su juventud de obras de pensadores italianos ${ }^{2}$. Su educación, sus enormes recursos financieros, su posición social como cabeza de la iglesia castellana y su proximidad al poder político, le permitieron iniciar proyectos artísticos que tienen un transfondo humanista. Como arzobispo de Toledo encargó en 1489 la sillería baja del coro de la catedral a Rodrigo Alemán. Esta obra incluye 54 relieves mostrando episodios militares de la Guerra de Granada en escenas de gran expresividad, conjunto absolutamente innovador en el panorama de las sillerías corales. Envuelto en formas tardogóticas y arropado por la función litúrgica del mueble, se ha incorporado en la sillería un programa de propaganda política para reforzar la posición del rey Fernando en Castilla. Las raíces de esta sutil interrelación entre religión y política hay que buscarlas en las ideas humanistas del Renacimiento italiano que habían calado en el pensamiento del cardenal ${ }^{3}$.

No es la sillería toledana el único proyecto iniciado por Mendoza en el que se adivina una cierta ruptura con la tradición tardogótica. Merece la pena recordar el

1 D. HEIM, Rodrigo Alemán und die Toledaner Skulptur um 1500. Studien zum künstlerischen Dialog in Europa, Kiel, 2006, pp. 196-204.

2 F. VILCHES VIVANCOS, "El Cardenal Mendoza: la familia, la vida y el personaje", Wad-al-Hayara, 22 (1995), pp. 22, 32; y F. VILCHES VIVANCOS, El Cardenal Mendoza. Datos biográficos definitivos y obra literaria, Guadalajara, 1995, p. 10.

3 D. HEIM, op. cit., 2006, pp. 146-148. 
caso del Colegio de Santa Cruz en Valladolid (1487-1491), obra de Lorenzo Váz$q \mathrm{qu}^{4}$. Se ha indicado en la bibliografía que no se acerca lo ejecutado en Valladolid a las obras más avanzadas de entonces en Italia, con un Renacimiento plenamente asentado $^{5}$. Pero contemplando la fachada del Colegio de Santa Cruz en el contexto arquitectónico del Valladolid de la época -pensamos, por ejemplo, en San Gregorio (1488-1496) - resulta evidente que el nuevo colegio del cardenal debió representar un auténtico terremoto para promotores y arquitectos de la ciudad castellana.

Sirvan estos dos ejemplos para ilustrar el papel decisivo que corresponde al promotor de las obras artísticas. Resulta paradójico a este respecto que Mendoza nunca hubiera estado en Italia y tan solo pudiera conocer lo que allí se hacía a través de sus colecciones o del arte gráfico. Un caso distinto es el de su sucesor, el arzobispo Francisco Jiménez de Cisneros (1436-1517). Está documentado un viaje a Italia del joven clérigo hacia 1470, permaneciendo durante varios meses en Roma ${ }^{6}$. Sabemos muy poco, demasiado poco, de este viaje, del que existen escasas informaciones en la historiografía a pesar de ser fundamental para entender el gusto artístico de quien es considerado por muchos, y con razón, como una figura clave en la introducción del Renacimiento en Castilla.

La apertura de nuevos horizontes que un viaje a Italia provocaba fue precisamente la razón que llevó a algunos promotores a enviar allí a sus artistas favoritos. De nuevo nos tenemos que referir al cardenal Mendoza, quien financió el viaje de Lorenzo Vázquez en $1491^{7}$. A su vuelta, el arquitecto realizó, colaborando con un taller genovés, el Palacio de La Calahorra para el hijo del cardenal, el marqués del Cenete, impresionante edificio netamente renacentista ${ }^{8}$.

Pero también encontramos durante el siglo XV el caso de artistas preocupados por las nuevas ideas, quienes, sin la ayuda y protección de un mecenas, se aventuraban en un largo viaje a Italia, fiados únicamente de su saber hacer y su talento. Entre estos intrépidos artistas castellanos destaca el pintor Pedro Berruguete, cuya obra consideramos claramente enmarcada en la estética renacentista, lo que solo se puede explicar aceptando una estancia en Italia, con independencia de la discusión que a este respecto se mantiene en la historiografía9 ${ }^{9}$ Durante más de diez años,

4 R. DÍEZ DEL CORRAL GARNICA, Arquitectura y mecenazgo. La imagen de Toledo en el Renacimiento, Madrid, 1987, pp. 28-30.

5 J. YARZA LUACES, Los Reyes Católicos. Paisaje artístico de una monarquía, Madrid, 1993, p. 325.

6 A. IGUAL ÚBEDA, El Cardenal Cisneros, Barcelona, 1957, pp. 19-23; y J. GARCÍA ORO, El Cardenal Cisneros. Vida y empresas, 2 vols., Madrid, 1992-1993, vol. I, p. 30.

7 A. GARCÍA LÓPEZ, "La correspondencia del conde de Tendilla. Nuevos datos sobre el mecenazgo de la familia del Cardenal Mendoza", Wad-al-Hayara, 22 (1995), p. 84.

8 M. FALOMIR FAUS y F. MARÍAS, "El primer viaje a Italia del Marqués del Zenete", Anuario del Departamento de Historia y Teoría del Arte, 6 (1994), p. 108; y R. DÍEZ DEL CORRAL GARNICA, op. cit., 1987, p. 24.

9 Sobre esta discusión, véase especialmente P. SILVA MAROTO, "Pedro Berruguete en Castilla", Pedro Berruguete y su entorno, Actas del Simposium Internacional, Palencia, 2004, pp. 23 y 26-38 у PH. 
tras volver de Italia, Berruguete y su taller trabajaron para el cabildo toledano, realizando numerosos frescos en el claustro catedralicio y en la catedral misma ${ }^{10}$. Desgraciadamente solo se ha conservado una pequeña parte de su obra toledana, lo que complica una valoración de la influencia que pudo tener este artista en la renovación de las formas artísticas en Toledo.

Otro factor determinante en la introducción de novedades en las distintas ramas artísticas era la difusión alcanzada por las estampas, gracias a las nuevas técnicas de reproducción. El arte gráfico desempeñó un papel fundamental en la difusión de motivos y elementos estilísticos. Rodrigo Alemán usaba frecuentemente los precedentes gráficos, sobre todo estampas tardogóticas del Alto Rin, como inspiración para su obra ${ }^{11}$. Por otro lado, Isabel Mateo pudo establecer en su día la utilización por este artista de un grabado de Antonio del Pollaiuolo como modelo para algunos motivos de las misericordias de la sillería de la catedral de Ciudad Rodrigo $(1498-1505)^{12}$. Este ejemplo sirve para demostrar que el conocer algún grabado no implicaba la adopción inmediata y completa de unas determinadas formas artísticas. En el presente caso, la estampa se utilizó como fuente de motivos y no de un determinado estilo.

Estos artistas viajeros, españoles que van a Italia o italianos que atienden encargos en la Península Ibérica, son probablemente el fermento decisivo que provoca el cambio de estilo. En su equipaje no faltarían estampas y dibujos que, junto a sus propias obras, difundían una forma distinta de entender el arte. Sin embargo, la existencia de patronos curiosos y amantes de las novedades es también imprescindible para que fructifiquen los encargos y se ejecuten las obras que jalonarán el cambio estilístico. Es decir, también el dinero tiene su papel en esta historia.

Volvamos ahora a nuestro punto de partida: la estancia de Andrea Sansovino en Toledo. En la obra de uno de los más importantes entalladores de la catedral, Rodrigo Alemán, ya se pueden atisbar ciertos rasgos relacionados con el Renacimiento y anteriores a aquel verano de 1500. ¿Cómo habían llegado estos nuevos elementos a integrarse en el repertorio de un entallador tardogótico sin que mediara un contacto directo con el arte italiano? Esta es la cuestión que intentamos aclarar pues la respuesta puede servir para entender mejor el proceso de intercambio de conocimientos entre artistas, incluso de disciplinas diferentes, así como los métodos de trabajo y renovación de los talleres.

LORENTZ, "Pedro Berruguete e Italia: ¿un simple caso historiográfico o una hipótesis seria?”, Pedro Berruguete y su entorno, Actas del Simposium Internacional, Palencia, 2004, pp. 51-63.

10 P. SILVA MAROTO, Pedro Berruguete, Salamanca, 1998, pp. 244-245. Marías y Pereda reducen el periodo de actividad de Berruguete en Toledo, pues consideran que su primer trabajo en la ciudad se remonta a 1488. F. MARÍAS y F. PEREDA, "Petrus Hispanus en Urbino y el bastón del Gonfaloniere: El problema Pedro Berruguete en Italia y la historiografía española", Archivo Español de Arte, 75 (2002), pp. 376-379.

${ }^{11}$ D. HEIM, op. cit., 2006, pp. 263-282.

12 I. MATEO GÓMEZ, "La batalla de los gigantes de Pollaiuolo en la sillería del coro de Ciudad Rodrigo", Boletín del Seminario de Estudios de Arte y Arqueología, 55 (1989), pp. 369-370. 


\section{Las intarsias de la sillería coral de la Catedral de Plasencia}

En la sillería realizada por Rodrigo Alemán para la catedral de Plasencia ya se encuentran muchos elementos que anuncian el Renacimiento. El artista creó entre 1497 y 1508 una espléndida obra con 67 sitiales (fig. 1). La sillería pla-

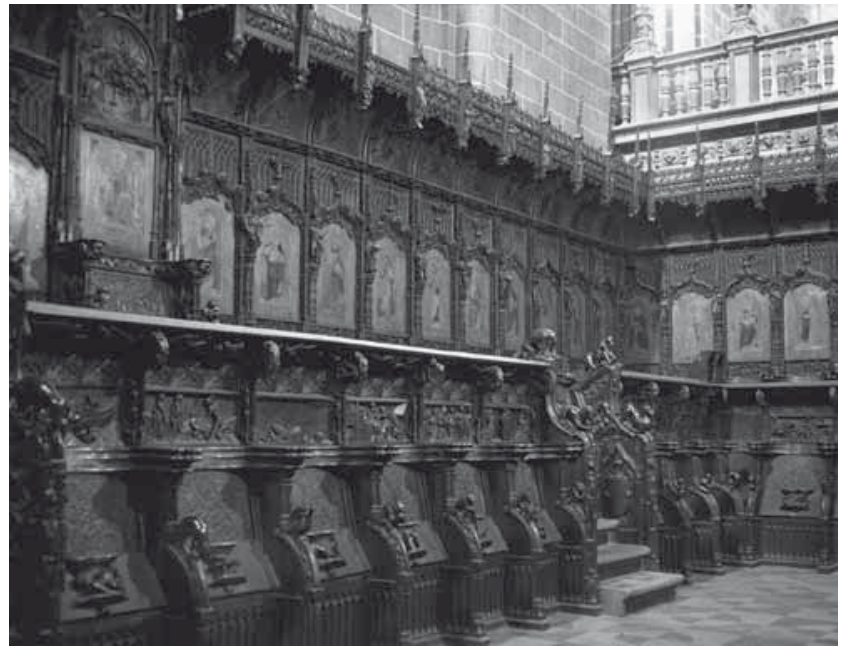

Fig. 1. Rodrigo Alemán, Sillería, Catedral de Plasencia, 1497-1508. centina presenta una rica decoración figurativa, no solo en la fila baja de sillas, como en Toledo, sino también en los sitiales altos. El elemento que la distingue de sus contemporáneas en España es el conjunto de tableros de la fila alta, en los que se han representado imágenes de santos usando la técnica de la intarsia ${ }^{13}$. En los sitiales de los extremos oriental y occidental de la fila alta, los tableros incluyen sendos retratos de los Reyes Católicos, mientras que la silla del obispo aparece decorada con una imagen de San Pedro como papa. El conjunto de las intarsias es magnífico, imprimiendo un carácter de mueble valiosísimo a la sillería.

Pocas son las imágenes representadas frontalmente. Los santos están ligeramente ladeados, simulando un diálogo silencioso entre ellos. Tal y como existe una jerarquía en los asientos, los santos representados también guardan un cierto orden dependiendo de su importancia, aunque su colocación ha sufrido modificaciones debidas al traslado y montaje de la sillería en el coro de la nueva catedral durante el siglo XVI ${ }^{14}$. En torno a San Pedro se alinean, primeramente, los apóstoles, seguidos de los Padres de la Iglesia, los evangelistas y otros santos importantes. El ciclo se cierra con los retratos de los Reyes Católicos, en cada uno de los extremos de la fila.

13 Véase la definición de intarsia en M.P. AGUILÓ ALONSO, El mueble en España siglos XVI-XVII, Madrid, 1993, p. 424.

14 En 1544 la construcción de la nueva catedral estaba tan avanzada que se decidió desmontar y almacenar la sillería. Ésta no sería de nuevo montada hasta 1565, en la nave central de la catedral nueva, más ancha que aquella de la vieja, ocupando un solo tramo. H.L. ARENA, Die Chorgestühle des Meisters Rodrigo Alemán (tesis doctoral), Heidelberg, 1965, pp. 48-49, docs. en las notas 66 y 68. 


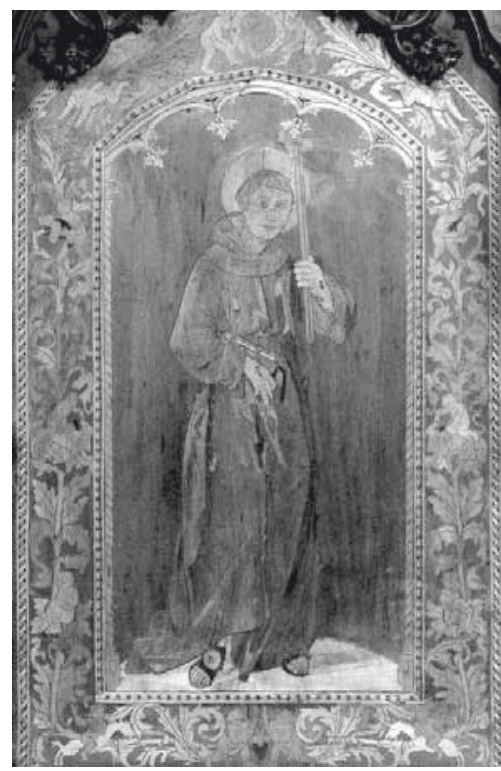

Fig. 2. Rodrigo Alemán, Sillería, detalle con San Francisco de Asís, Catedral de Plasencia, 1497-1508.
Salvo la de San Pedro, las figuras aparecen rodeadas por un marco o friso (fig. 2), ancho e intarsiado con decoración vegetal combinada con representaciones de animales salvajes, dragones, hombres y angelillos, todo ello delimitado por finas regletas con elementos geométricos repetidos, destinados a crear la ilusión de profundidad y volumen. Adosadas al interior de los mismos se han representado columnas espirales, también en intarsia, que soportan un arco lobulado con florones.

La técnica utilizada en las regletas es la de tarsia a toppo, proveniente del arte islámico y desarrollada en Italia durante los siglos XIII y $\mathrm{XIV}^{15}$. Se emplea sobre todo en frisos decorativos, a menudo con efectos de perspectiva. En la elaboración de estos elementos se usaban listones estrechos de distintas maderas, generalmente de sección cuadrangular, de los que se iban cortando pequeñas láminas que eran pegadas sobre un soporte, formando una especie de mosaico con formas geométricas ornamentales. Las regletas podían ser preparadas en gran cantidad y con independencia de la obra en la que se incluían.

La recreación del espacio fue una de las principales preocupaciones del autor de las intarsias. Aunque el fondo de las figuras solamente muestra los juegos de colores naturales de la madera, se han utilizado éstos sabiamente para transmitir la ilusión de la existencia de un nicho entre dos columnas. El efecto buscado de perspectiva y volumen es aún más acentuado en las representaciones de los reyes y de San Pedro, particularmente en el tratamiento de los brazales y laterales del trono del apóstol y en su figura misma.

Para las figuras de los tableros, se han utilizado también piezas de distintas formas y maderas. El intarsiador se ha valido de sus diferentes estructuras y colores para aumentar la plasticidad de las imágines y la ilusión de volumen. Característico en estas intarsias placentinas es el acusado contraste entre el manto o capa, muy oscuro, y las vestiduras claras, o viceversa. Se acentúa así el carácter pictórico, reforzado por los efectos de claroscuro que las diferencias de tonos de las maderas

15 La técnica de mosaico en bloque fue tomada originalmente del arte islámico. Para elaborar líneas muy finas se pegaban distintas hojas de madera. H. MICHAELSEN y R. BUCHHOLZ, Vom Färben des Holzes. Holzbeizen von der Antike bis in die Gegenwart, Petersberg, 2006, pp. 36-37; F. WINDISCH-GRAETZ, Möbel Europas. Von der Romanik bis zur Spätgotik. Mit einem Rückblick auf Antike und Spätantike, München, 1982, vol. 1, p. 100; y M.P. AGUILÓ ALONSO, op. cit., 1993, p. 162. 
crean en las arrugas y pliegues. También es llamativo el uso de elementos decorativos que cubren amplias superficies de las figuras y están realizados con trazos incrustados y rellenos con pasta negra. Con ellos se pretende recrear vestiduras valiosas de brocado y también aumentar el volumen de las telas, dotadas además de dobladillos ricamente decorados con piedras preciosas. Esta misma técnica de dibujo con pasta negra se ha utilizado para modelar los rostros y los cabellos de las figuras e individualizarlas.

¿De dónde provienen estas intarsias? Ante la ausencia de respuestas convincentes y fundadas, se ha optado en la historiografía por considerar este conjunto como una obra añadida a la sillería con posterioridad a su construcción, sin aportar ningún argumento en apoyo de esta afirmación. La inclusión de elementos ornamentales inequívocamente renacentistas en las intarsias, cuyo uso estaba muy poco extendido en Castilla en la época en la que se construyó la sillería, parece ser la única razón que podría apuntar hacia una realización más tardía de los tableros ${ }^{16}$. El desmontaje de la sillería en $1544^{17}$, consecuencia de los trabajos de construcción de la catedral nueva, y la existencia de un sitial separado, hoy en el Museo Nacional de Escultura Policromada de Valladolid, son las razones de más peso aducidas como soporte de esta hipótesis. El sitial ahora en Valladolid sería, siguiendo esta línea de razonamiento, el estalo original de la sillería reservado al obispo, sustituido por el sitial actual con el tablero intarsiado representando a San Pedro ${ }^{18}$.

Tras un análisis detallado, no tardan en surgir problemas para poder aceptar la hipótesis de una incorporación posterior de las intarsias ${ }^{19}$. En primer lugar, resulta extraño que apenas 50 años después de construida la sillería por Rodrigo Alemán,

16 R.J. MÉLIDA, Catálogo monumental de España. Provincia de Cáceres, 2 vols., Madrid, 1924, pp. 287-288; H.L. ARENA, "Las sillerías de coro del maestro Rodrigo Alemán. Las sillerías del gótico tardío en España", Boletín del Seminario de Estudios de Arte y Arqueología, 32 (1966), pp. 102-106; y J.I. HERNÁNDEZ REDONDO y M. ARIAS MARTÍNEZ, "La silla de Rodrigo Alemán en el Museo Nacional de Escultura", Homenaje al Profesor Martín González, Valladolid, 1995, p. 379.

17 Véase nota 14.

18 J.I. HERNÁNDEZ REDONDO y M. ARIAS MARTÍNEZ, op. cit., 1995, p. 379. Tres son las razones aducidas para suponer que los tableros intarsiados no son obra del taller de Rodrigo Alemán. En primer lugar, la técnica de la intarsia en sí misma, extraña a un artista de formación nórdica. Por otro lado, las formas claramente renacentistas que se aprecian en los marcos de los tableros y en el trono de San Pedro, desconocidas en el panorama artístico castellano de 1498. Por último, el acusado contraste entre estos tableros y los de la catedral de Ciudad Rodrigo, obra posterior de Rodrigo Alemán enmarcada en la tradición tardogótica. Estos autores no consideran que la representación de los Reyes Católicos implique una ejecución de los tableros durante el reinado de los mismos, citando la fachada de la Universidad de Salamanca, obra posterior donde aparecen los monarcas, como contraejemplo. J.I. HERNÁNDEZ REDONDO y M. ARIAS MARTÍNEZ, op. cit., 1995 , p. 379.

19 Sin entrar en muchos detalles ni dar razones, algunos autores no expresan dudas sobre la realización contemporánea de sillería y tableros intarsiados. Véase P. MOGOLLÓN CANO-CORTÉS y F.J. PIZARRO GÓMEZ, "La sillería de coro de la catedral de Plasencia y su tiempo", La sillería del coro de la catedral de Plasencia, Cáceres, 2005, p. 150; P. MOGOLLÓN CANO-CORTÉS y F.J. PIZARRO GÓMEZ, La sillería de coro de la catedral de Plasencia, Cáceres, 1992, p. 35; Reyes y Mecenas. Los Reyes Católicos - Maximiliano I y los inicios de la Casa de Austria en España, Toledo, 1992, cat. 162; y J. YARZA LUACES, op. cit., 1993 , p. 72. 
inversión extraordinariamente onerosa para el cabildo placentino, se decidiera la sustitución de partes importantes de la obra de este artista, muy apreciado en la ciudad, por otras también costosas, y esto en un momento en el que los enormes gastos que ocasionaba la construcción de la catedral nueva agotaban los recursos del cabildo ${ }^{20}$. Además algunos detalles constructivos de la sillería misma parecen no encajar con la posible sustitución. Así, por ejemplo, las medidas del sitial de Valladolid son bastante menores que las de la cátedra de la sillería y no se corresponden con las de los otros sitiales, altos o bajos, de la misma ${ }^{21}$. La coherencia de las decoraciones de los marcos tallados e intarsiados es también una indicación de construcción simultánea y no de adaptación posterior ${ }^{22}$. El uso de un mismo motivo en la misericordia y brazales del sitial del obispo en Plasencia y en el sitial de Valladolid no se ajusta a la práctica habitual de Rodrigo Alemán, quien evitaba repeticiones en una misma obra. Hay otros elementos intarsiados en otras partes de la sillería, como son los respaldos de los sillas altas, las puertas hoy desmontadas y las inscripciones en los marcos tallados de las escenas, que representan claros indicios de ejecución simultánea de elementos de talla y de intarsias.

Queremos apuntar como último argumento para considerar que intarsias y sitiales corresponden a un único proyecto el precio pagado por el cabildo placentino. En el contrato de 7 de Junio de 1497 entre Rodrigo Alemán y el cabildo de la catedral de Plasencia, se acuerda un precio de 30.000 mrs para cada uno de los sitiales de honor de los reyes, cantidad que se aumentó hasta los $35.000 \mathrm{mrs}$ tras la tasación efectuada al terminarse los mismos. Es éste un precio exagerado, que corresponde a entre dos y cuatro veces lo pagado por los sitiales de sillerías contemporáneas, como las de Toledo, Sevilla, Ciudad Rodrigo y Zamora ${ }^{23}$. Semejan-

20 La posterior evolución del proyecto, con numerosos periodos sin actividad debido a la falta de dinero, prueba que con la envergadura de una nueva catedral se alcanzaba el límite de las capacidades económicas del cabildo. J.M. LÓPEZ MARTÍN, "El sistema de financiación y de organización de las obras de la nueva catedral de Plasencia en el siglo XVI”, VIII. Centenario de la diócesis de Plasencia (1189-1989), Jornada de Estudios históricos, Plasencia, 1990, pp. 498-499.

21 El tablero intarsiado del sitial episcopal mide $59 \mathrm{~cm}$ de ancho, mientras que el relieve de San Pedro del estalo de Valladolid solo tiene $47 \mathrm{~cm}$ de ancho. El ancho total de la cátedra en Plasencia es de $80 \mathrm{~cm}$, mientras que el sitial de Valladolid tiene $71 \mathrm{~cm}$ de ancho. Es decir, las medidas de ésta última silla son sensiblemente inferiores a las del estalo episcopal placentino y parecen corresponder más bien a las de una silla confesionario, como ha venido siendo considerada tradicionalmente en Plasencia. D. HEIM, op. cit., 2006, pp. 83-84.

22 Tan sólo es posible distinguir las huellas de una adaptación a una nave más ancha en la esquinas de la sillería alta.

${ }^{23}$ Comparados con Sevilla donde Pyeter Dancart recibe en el año 147818.000 mrs por cada silla tras la tasación, los sitiales placentinos costaron casi el doble. D. y H. KRAUS, Las sillerías góticas españolas, Madrid, 1984, pp. 165-166. Aún mayores son las diferencias con las sillas de Ciudad Rodrigo y Toledo, por las que Rodrigo Alemán recibió 13.000 y 10.380 mrs respectivamente. D. HEIM, op. cit., 2006, p. 97; y La sillería coral de la Catedral de Ciudad Rodrigo, Madrid, 2009, p. 20. Según el contrato de 1503, Juan de Bruselas cobraba en Zamora $6.000 \mathrm{mrs}$ por cada silla alta que no tuviera una silla baja delante, precio que se incrementaba a 9.000 mrs por cada conjunto de sillas alta y baja. En este precio no se incluía el coste del material ni el salario de los oficiales del maestro, que iban por cuenta del cabildo. L. VASALLO TORANZO, "El cabildo de la catedral de Ciudad Rodrigo contra Rodrigo Alemán”, Archivo Español de Arte, 72 (1999), p. 201, nota 7. 
te diferencia, incluso con las sillerías toledana y sevillana, significa que estos dos sitiales de coro son probablemente los más caros construidos en Castilla en esta época. Incluso admitiendo que los precios no son absolutamente comparables, por las diferentes valoraciones regionales del maravedí, así como por las distintas cláusulas de los contratos, que podían incluir o no el coste del material en el precio acordado, las diferencias son tales que podemos concluir que estamos ante dos piezas consideradas como excepcionales por su técnica y virtuosidad por los promotores de las mismas.

Los sitiales reales destacan en el conjunto de la sillería por sus tableros intarsiados y los chapiteles que los coronan. Su sola contemplación transmite la sensación de estar ante muebles valiosos y complejos. El chapitel, a pesar de su aparatosidad, se construyó utilizando elementos relativamente sencillos, que podía preparar de manera más o menos mecánica un entallador. Por tanto, la única justificación que encontramos para el precio de los sitiales es la inclusión de los tableros intarsiados, que tenían que ser obra de un especialista, a medio camino entre pintor y entallador, que no abundaba y que tenía que trabajar largas horas seleccionando y preparando la madera y ajustando finísimas piezas. La singularidad de esta labor es la que provoca un precio también excepcionalmente alto.

El lenguaje formal de las representaciones de santos en los tableros intarsiados también se puede datar hacia 1500 , si se admite que se trata de una obra de un artista italiano, como veremos posteriormente. Sin embargo, aceptar que los tableros formaban parte ya de la sillería original nos plantea dos cuestiones fundamentales. En primer lugar, ¿por qué incluyo Rodrigo Alemán tableros con intarsias en la sillería de Plasencia? ¿Cómo pudo un taller como el de Rodrigo Alemán, diestro en talla pero absolutamente inexperto en la técnica de la intarsia, llevar a cabo esta obra, incorporando las intarsias?

\section{Tableros intarsiados en las sillerías corales española}

La respuesta a las cuestiones anteriores ha de iniciarse rastreando entre lo que se hacía en España en esta época utilizando esta técnica e intentar así ubicar los tableros placentinos. Son pocas las sillerías tardogóticas españolas que poseen tableros intarsiados de cierta entidad. Las más importantes son las de Oviedo y Sevilla.

La sillería de Oviedo, obra de maestros extranjeros desconocidos, no se puede datar con certeza por la falta de datos en los archivos. Están documentados trabajos en 1492, estando la sillería ya montada en el coro en $1497^{24}$. Las sillas de la fila superior tienen tableros dorsales de casi dos metros de altura decorados con taraceas.

24 F. DE CASO FERNÁNDEZ, La construcción de la catedral de Oviedo (1293-1587), Oviedo, 1981, doc. 88-90 en las pp. 66-68; D. y H. KRAUS, op. cit., 1984, pp. 24-26; y M.D. TEIJEIRA PABLOS, La sillería de coro de la catedral de Oviedo, Oviedo, 1998, pp. 27-32. 
Rodeadas por decoración vegetal o geométrica, se han dispuesto citas de la Biblia, bajo las cuales aparecen, en dos planos, armas, cruces y ornamentos geométricos. Estos tableros, con piezas claras de madera de haya incrustadas en el nogal más oscuro del tablero, recuerdan vagamente, tanto por los motivos como por la técnica utilizados, las obras de taracea de tradición mudéjar, desprovistas de decoración figurativa y centradas en motivos vegetales o geométricos ${ }^{25}$. La comparación de estos paneles con los de Plasencia, dotados de una decoración rica, expresiva y figurativa, no hace sino aumentar la apariencia arcaica que presentan los ovetenses. No se han utilizado en ellos las diferencias de tonos y colores de las maderas, o mejor dicho solo se han utilizado dos colores, por lo que su ornamentación es bidimensional, sin atisbo de perspectiva, intentando imitar miniaturas de manuscritos, o las cortinas y tejidos que se disponían sobre los muros tras los sitiales del coro en la Edad Media ${ }^{26}$. Es posible que la primitiva sillería ovetense dispusiera de estas telas y por ello se buscó recrearlas con las taraceas.

El efecto que producen las intarsias de la sillería coral de Sevilla, iniciada hacia 1470 por Nufro Sánchez y terminada en 1479 o 1480 por Pyeter Dancart, es bien distinto $^{27}$. La atención del observador es inmediatamente atraída por los tableros, presentes tanto en la fila alta, sobre relieves tallados, como en los respaldos de los sitiales. Los tableros de la fila alta se decoran con motivos mudéjares geométricos, coronados por un friso con decoración también geométrica en perspectiva. Están rodeados por un marco con ornamentación vegetal o geométrica. Los respaldos de las sillas bajas repiten un único motivo: una vista, en perspectiva bastante simple, de la Giralda. Las intarsias sevillanas, con la repetición de motivos hasta cubrir la superficie del tablero, son claramente deudoras de la tradición mudéjar. La principal novedad respecto a las intarsias de Oviedo viene representada por el uso de la tarsia a toppo, también utilizada en Plasencia. El intento de dotar a la representación de la Giralda de una cierta perspectiva implica un alejamiento de las formas mudéjares. La imagen de la torre requiere, además, la introducción de numerosos detalles en un espacio relativamente pequeño, lo que le confiere el aspecto de un dibujo.

Como hemos indicado, estos son los principales ejemplos de intarsias en sillerías corales españolas contemporáneas de la sillería de Plasencia. Basta compararlas a simple vista con los tableros placentinos para comprender que media un abismo artístico entre aquellas y éstos, tanto en lo técnico como en lo artístico. Por tanto, el origen de los tableros intarsiados placentinos no parece estar en la evolu-

25 Reyes y mecenas, op. cit., 1992, nota 19, cat. 141. Véase también M.D. TEIJEIRA PABLOS, "El uso de la marquetería en las sillerías corales tardogóticas: El caso ovetense", Boletín del museo e instituto Camón Aznar, 59-60 (1995), pp. 241-242; у op. cit., 1998, p. 88.

${ }^{26}$ Sobre las cortinas y telas y su influencia en las sillerías góticas españolas, véase D. HEIM, op. cit., 2006, pp. 135-137.

27 I. MATEO GÓMEZ, "La sillería del coro de la catedral de Sevilla”, D. Angulo Iñiguez et alii, La catedral de Sevilla, Sevilla, 1991, p. 321; y J. GUERRERO LOVILLO, Guía artística de Sevilla, Sevilla, 1986, p. 76. 
ción de lo que se hacía en España en esta época. Hay que dirigir la mirada hacia Italia, donde el arte de la intarsia alcanzaba por estos años su punto culminante. Sí, pero ¿dónde en Italia? ¿En cual de las corrientes o escuelas en el arte de la creación de intarsias hay que ubicar a los tableros de Plasencia?

\section{Intarsias figurativas en Italia}

Es en la Toscana, concretamente en Siena o quizás Florencia, donde empezaron a desarrollarse las intarsias decorativas italianas a partir de los siglos XIII o XIV, siendo utilizadas particularmente en muebles para las iglesias ${ }^{28}$. Los limitados conocimientos técnicos confinaron estos trabajos iniciales a la realización de composiciones ornamentales, para las que era suficiente con utilizar dos distintas maderas que tuvieran suficiente contraste cromático. En estas primeras tarsia a toppo, los artesanos utilizaron principalmente nogal, bonetero, peral y roble negro ${ }^{29}$.

El arte de la intarsia experimentó un desarrollo espectacular en la Italia del siglo XV. Pasó de ser un elemento secundario decorativo, basado en formas geométricas, a constituir el elemento principal de obras de primer orden en las que se conjugaba la representación de figuras, paisajes o edificios imaginarios con complicadas escenas y ejercicios de perspectiva. En las primeras décadas de dicho siglo, fueron sobre todo artífices sieneses los que impulsaron esta técnica. En este sentido, señalaremos las intarsias para la sillería de la capilla del Palazzo Pubblico de Siena, obra realizada entre 1415 y 1428 por Domenico di Niccolò dei Cori (hacia 13631453) y su discípulo Mattia di Nanni (1403-1433). Se trata de las intarsias figurativas más antiguas que han llegado hasta nosotros. En los 22 tableros de los dorsales existentes en los sitiales se han representado los misterios del Credo, creando un modelo que será reproducido en otras sillerías ${ }^{30}$.

Domenico di Niccolò, un artista extraordinariamente versátil y de gran fama, desarrolla en la obra mencionada una serie de novedades técnicas e iconográficas que influirán decisivamente en las intarsias posteriores. Novedosa es la incorporación de figuras creadas con distintas maderas ${ }^{31}$. Las diferentes estructuras y coloraciones de éstas fueron usadas con gran habilidad para crear contrastes de luz y delinear rasgos y vestiduras. Este intarsiador utilizó para ello un repertorio de maderas muy amplio e inusual en esta época, no dudando además en tintar alguna

28 La ciudad de Siena es citada frecuentemente como el centro temprano de esta técnica. Sin embargo, Thomas Rohark ha llamado la atención recientemente sobre la existencia documentada en Florencia de intarsias, hoy perdidas, que se remontan al siglo XIV. T. ROHARK, Intarsien. Entwicklung eines Bildmediums in der italienischen Renaissance, Göttingen, 2007, pp. 49-50.

29 H. MICHAELSEN y R. BUCHHOLZ, op. cit., 2006, p. 37.

30 F. BOESPFLUG, Le Credo de Sienne, París, 1985, p. 6; y F. WINDISCH-GRAETZ, Möbel Europas. Renaissance und Manierismus. Vom 15. Jahrhundert bis in die erste Hälfte des 17. Jahrhunderts, vol. 2, Munich, 1983, p. 18.

31 T. ROHARK, op. cit., 2007, pp. 51-53. 
de ellas para conseguir un determinado color. Pastas coloreadas y pequeñas piezas metálicas completan el catálogo de materiales empleados, consiguiéndose un efecto de plasticidad hasta entonces desconocido en estos trabajos ${ }^{32}$.

El investigador Massimo Ferretti agrupó las intarsias italianas producidas durante la segunda mitad del siglo XV en dos grandes escuelas, cuyos límites son un tanto difusos. La primera se centra en torno al taller florentino de los hermanos Giuliano (1432-1490) y Benedetto da Maiano (1442-1497), cuyas obras influyeron en la región central de Italia, especialmente en la Toscana, las Marcas y Umbría. La segunda escuela, geográficamente extendida en el norte de Italia, especialmente en el valle del Po y en Venecia, gira en torno a la obra de la familia de artistas Canozi da Lendinara. Lorenzo (1425-1477) y Cristoforo da Lendinara (muerto en 1491) realizaron grandes conjuntos de intarsias. Podríamos añadir, con ciertos reparos, una tercera escuela o corriente, cuyas obras, localizadas en la Lombardía, son tan heterogéneas y muestran tantos nexos con aquellas de los Lendinara que no parecen sino ser una derivación de la escuela de éstos ${ }^{33}$.

Lorenzo y Cristoforo da Lendinara, procedentes de Rovigo, entraron en contacto con Piero della Fancesca hacia 1450 en la corte de Ferrara. Sus obras más importantes se encuentran en Módena y en Padua. En las intarsias de la sillería coral de la catedral de Módena, realizada entre 1461 y $1465^{34}$, los hermanos Lendinara experimentaron con una serie de motivos geométricos que se enmarcan en la tradición de estas obras. Paulatinamente fueron desarrollando representaciones con mayor sentido espacial ${ }^{35}$. Sus amplias intarsias se basan probablemente en diseños de Piero Della Francesca y muestran, sobre todo, conjuntos arquitectónicos ideales, especialmente notables en lo que ha llegado hasta nosotros de la sillería de Padua (1462-1469), con un cuidado estudio de la perspectiva.

El taller de los Lendinara realizaba representaciones de figuras de medio cuerpo sobre un fondo negro, lo que aumentaba el sentido espacial, incrementado en las de la sillería de la Catedral de Módena (1477) por las ventanas con arco que las enmarcan, sin alcanzar el nivel de profundidad de las arquitecturas en los paneles de Padua. En las piezas de madera relativamente grandes que forman las intarsias, los efectos ópticos de las composiciones y su cromatismo se acentúan por el hábil uso que ha hecho el artista de las distintas estructuras de las maderas ${ }^{36}$. El volumen de

32 Los efectos cromáticos en esta sillería se completan con la incorporación de finas líneas de hueso, metal y pastas coloreadas en verde y rojo. H. MICHAELSEN y R. BUCHHOLZ, op. cit., 2006, p. 39.

33 M. FERRETTI, "I maestri della prospettiva", Storia dell'arte italiana, vol. 11, Turín, 1982, p. 495.

34 A. PUERARI, "Le tarsie del Platina (1477-1490)", Paragone, 205/25, 18 (1967), p. 5; y H. MICHAELSEN y R. BUCHHOLZ, op. cit., 2006, p. 40.

35 M. FERRETTI, op. cit., 1982, pp. 497-498.

36 A. CHASTEL, Italienische Renaissance: Die Ausbildung der großen Kunstzentren in der Zeit von 1460 bis 1500, Munich, 1965, pp. 246-247; y H. FLADE, Intarsia. Europäische Einlegekunst aus sechs Jahrhunderten, Munich, 1986, p. 61. 
las vestiduras y el contraste de los pliegues se consiguen principalmente con la sola diferencia de tonos de una misma pieza debida a la estructura de la madera. Así, por ejemplo, se reconoce claramente como tal la barba del San Jerónimo del coro de la Catedral de Módena ${ }^{37}$, con la configuración del vello, gracias a los cambios cromáticos debido a las nervaduras de las dos únicas piezas que la forman ${ }^{38}$.

Otra característica técnica de la obra de este taller es la ausencia de líneas de contorno de las figuras. Los límites de éstas quedan fijados exclusivamente por las diferencias de colores entre las piezas. La precisión en el trabajo de selección y adaptación de éstas hace innecesaria la presencia de líneas que las delimiten. Esto es particularmente visible en las figuras de los evangelistas realizadas por Cristoforo da Lendinara en 1477, actualmente en una de las naves laterales de la Catedral de Módena ${ }^{39}$. Entre los rasgos característicos de la obra de este taller están también los expresivos ojos de las figuras, compuestos con una madera muy oscura ${ }^{40}$, que atraen la atención del observador y confieren un carácter especialmente enérgico a las representaciones frontales.

Bajo la influencia de Lorenzo y Cristoforo da Lendinara no solamente podemos encontrar trabajando a miembros más jóvenes de su familia, como Bernardino da Lendinara, sino también a toda una serie de discípulos, entre los que destacan Luchino Bianchino, Matteo Civitali, Pier Antonio degli Abbati y Giovanni Maria Palatina $^{41}$. Si consideramos que estos colaboradores crearon a su vez sus respectivos talleres se comprende la importancia que los Canozi da Lendinara tienen para el desarrollo de los trabajos de intarsia. El citado Giovanni Maria Palatina (14551500), nacido en Mantua, aplicó lo aprendido en el taller de los Lendinara en sus obras en la sillería coral (1483-1490) y el armario de la sacristía (1477-1480) de la catedral de Cremona, en las que se aprecia el uso de las diferencias cromáticas de las maderas y los efectos de la luz incidente en las figuras de medio cuerpo colocadas también bajo arcos de medio punto. Fueron estas intarsias de gran importancia para la difusión de las características de los Canozi da Lendinara en la Lombardía. En las obras de Palatina se ha prestado mayor atención a las diferencias cromáticas de las maderas, acentuadas con tratamientos químicos, que a los contrastes basados en las distintas estructuras de las piezas ${ }^{42}$.

37 El tablero formaba parte originalmente de la sillería ejecutada entre 1471 y 1477 para el coro de la cripta. T. ROHARK, op. cit., 2007, p. 226.

38 M. FERRETTI, op. cit., 1982, pp. 498-499.

39 Ibidem, pp. 499-500. En las descripciones del templo aparecen los tableros tanto como pertenecientes al coro como, más tarde, incluidos en la sacristía. T. ROHARK, op. cit., 2007, p. 227. Precisamente estas líneas y el tratamiento del volumen han llevado a Ferretti a proponer a Piero della Francesca como origen de las trazas.

40 A.M. WILMERING, The Gubbio studiolo and its conservation, II. Italian Renaissance intarsia and the conservation of the Gubbio studiolo, Nueva York, 1999, p. 95.

41 T. ROHARK, op. cit., 2007, p. 57.

${ }^{42}$ M. FERRETTI, op. cit., 1982, nota 33, pp. 511-512; y A. PUERARI, op. cit., 1967, pp. 7 y 16 . Los contenidos de sus intarsias se apartan de aquellos de los Canozi y tienen su origen en precedentes del norte de Italia. Ibidem, p. 12. 
La influencia del taller Canozi da Lendinara en Lombardía fue diluyéndose poco a poco. Pantaleone de Marchi se comprometía en 1492 a realizar 12 paneles intarsiados representando a los apóstoles, destinados a la sillería coral de la Cartuja de Pavía, cuyos paneles dorsales se han decorado además con figuras de santos, personajes del Antiguo Testamento y figuras eclesiásticas. El taller de Pantaleone de Marchi utilizaba incrustaciones doradas para semejar piezas metálicas, además de usar con profusión la coloración de la madera. Su técnica recuerda más aquella de los maestros vidrieros que la de los intarsiadores a la manera de los Lendinara o los Maiano. Con la coloración de la madera se amplió el repertorio de los motivos representados para incluir también paisajes. La obra de Pantaleone de Marchi creó escuela y halló continuadores en la Lombardía de principios del siglo $\mathrm{XVI}^{43}$.

De forma paralela a toda esta evolución en la Italia septentrional, se desarrolló durante la segunda mitad del siglo XV la otra gran escuela de trabajos de intarsia, en torno al taller florentino de los hermanos Maiano. Giuliano da Maiano recibió en 1463 el encargo de realizar el revestimiento con madera de las paredes de la sacristía de la Catedral de Santa Maria del Fiore en Florencia (fig. 3), terminado en 1468. Las paredes septentrional y meridional ya habían sido revestidas entre 1436 y 1445 por otros intarsiadores, quienes incorporaron en ellas el ejemplo más antiguo de trampantojo ${ }^{44}$. Las intarsias de las paredes oriental y occidental de la sacristía de Florencia son la primera obra segura de este

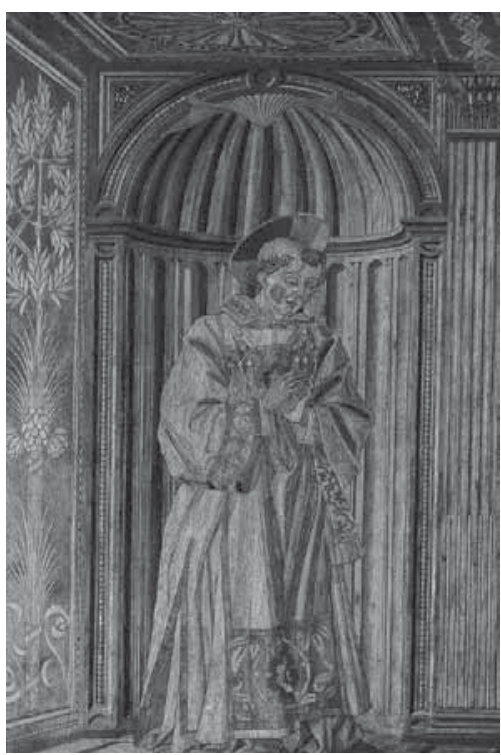

Fig. 3. Giuliano da Maiano, San Eugenio, Sacristía de la Catedral de Florencia, 1463-1468. tipo que conocemos de Giuliano da Maiano. En la pared oriental, frente a la entrada de la sacristía, se ha representado a San Cenobio, sentado y flanqueado por las figuras de San Eugenio y San Crescencio. El conjunto se corona con la escena

${ }^{43}$ M. FERRETTI, op. cit., 1982, pp. 513-515.

44 Antonio Manetti y Agnolo di Lazzaro d'Arezzo, entre otros, colaboraron en la decoración de la pared meridional. Véase la breve descripción y la bibliografía correspondiente en T. ROHARK, op. cit., 2007, pp. 215-216. En la pared septentrional se encuentran las representaciones más antiguas de armarios con puertas abiertas que dejan ver los objetos que guardan. Los paneles son el precedente directo de las representaciones en perspectiva para recrear un espacio constructivo que se usa en las intarsias, una consecuencia de la cooperación de Brunelleschi con maestros intarsiadores. C. DIGIESI, "Giuliano da Maiano e i lavori di legname a Firenze nella seconda meta' del XV secolo", La bottega di Giuliano e Benedetto da Maiano nel Rinascimento fiorentino, Fiésole/Florencia, 1994, p. 85. Este tipo de representación y, en particular, el motivo del armario con las puertas abiertas, alcanzó gran popularidad y uso extendido, de manera que incluso 70 años más tarde era todavía usado, por ejemplo, en los trabajos de Fra Giovanni da Verona. T. ROHARK, op. cit., 2007, p. 85. 
de la Anunciación, entre los profetas Amos e Isaías. La entrada en el muro occidental se decora con dos intarsias representando la Natividad y la Presentación de Jesús. La perfección técnica y los logrados efectos ópticos son las características más llamativas de estas intarsias.

Las representaciones de Giuliano da Maiano son bastante innovadoras. Además de incorporar las escenas en una representación espacial, como otras intarsias de la época, detallando el entorno de las figuras, las cuales aparecen con frecuencia rodeadas por arquitecturas que contribuyen a crear los efectos de perspectiva, siguiendo una concepción eminentemente pictórica, Da Maiano presta una gran atención a las figuras mismas, también representadas en perspectiva. Probablemente la idea proviene de los diseños preparados por pintores como Alessandro Baldovinetti o Tommaso Finiguerra, quienes, según la documentación conservada, recibieron encargos de da Maiano para preparar dibujos para las intarsias de la sacristía florentina ${ }^{45}$. Estas intarsias presentan una extraordinaria precisión y cuidado en su ejecución. Los contornos de las figuras y el dibujo interior de las mismas se han remarcado con finas líneas de madera negra. Los rostros y las manos han sido compuestos con una multitud de piezas de distintas maderas y colores a modo de mosaico. Los pliegues de las vestiduras se construyen con delgadas tiras de madera de distintos colores. A pesar de las limitaciones que impone el uso de una técnica como la intarsia, es evidente que Giuliano da Maiano ha intentado transportar la interpretación pictórica presente en los diseños, basada en la obtención de una sensación de volumen a través del juego de luces y sombras ${ }^{46}$.

Dos rasgos fundamentales de la obra del taller de da Maiano resultan particularmente evidentes en la sacristía florentina. Se trata de la composición técnica de las superficies de las maderas utilizadas y de la utilización de la perspectiva según los cánones establecidos por Filippo Brunelleschi, quien, según Vasari, había enseñado el resultado de sus estudios geométricos a algunos artífices de intarsias ${ }^{47}$. En el ensamblaje de las maderas, Giuliano da Maiano limitaba grandes superficies de un mismo tipo mediante pequeñas piezas o tiras de maderas de color distinto con las que realzaba el contorno al tiempo que era capaz de generar contrastes de

45 La Obra de la catedral de Florencia pagó a Giuliano da Maiano en 1463/1464 algunas cantidades a cuenta de los dibujos que, para las intarsias en la sacristía, ejecutó Tommaso Finiguerra, y que deberían ser coloreados por Alessandro Baldovinetti. M. HAINES, La sacrestia delle Messe del Duomo di Firenze, Florencia, 1983, p. 302; y F. QUINTERIO, Giuliano da Maiano. “Grandissimo domestico”, Roma, 1996, pp. 37-38. Según los documentos conservados, se representaba en estos dibujos a María con un ángel, probablemente la escena de la Anunciación, así como a San Cenobio con dos diáconos. Ferretti supone que la aportación del pintor a la perspectiva espacial debió ser poco importante. M. FERRETTI, op. cit., 1982, pp. 474-475 y 495.

46 Sobre las maderas y coloraciones utilizadas en las intarsias, véase H. MICHAELSEN y R. BUCHHOLZ, op. cit., 2006, nota 15, p. 40.

47 Giorgio Vasari refiere cómo Brunelleschi también enseñó reglas de perspectiva a los intarsiadores: “... nè restò di mostrare a quelli che lavoravono le tarsie.”. GIORGIO VASARI, Le vite de’ piú eccellenti architetti, pittori, et scultori italiani, da Ciambue, insino a'tempi nostri, Florencia, 1550, L. Bellosi y A. Rossi (eds.), 2 vols., Turín, 1991, vol. 1, p. 280. 
claroscuro sin necesidad de pirograbar líneas de dibujo. Es ésta una característica repetida en todas las intarsias florentinas ${ }^{48}$.

En el taller de Giuliano da Maiano se formaron muchos de los maestros que difundieron el arte de la intarsia durante la segunda mitad del siglo XV. Algunos de sus trabajos fueron exportados y sus obras influyeron en las intarsias realizadas en toda la Italia central ${ }^{49}$. La colaboración con otros renombrados entalladores de la ciudad favoreció enormemente la difusión de las intarsias florentinas. Citaremos a Francesco di Giovanni, il Francione (1428-1495), considerado como el iniciador de la escuela florentina de intarsia, Baccio d'Agnolo (1462-1543) y Baccio Pontelli $(1450-1491)^{50}$. Según la descripción del cronista Benedetto Dei, en 1472 existían 84 talleres dedicados a las intarsias solo en Florencia ${ }^{51}$.

\section{¿Un intarsiador italiano en Plasencia?}

Si ahora comparamos los tableros intarsiados de la sillería de Plasencia con las obras de estas dos grandes escuelas italianas, parece claro que las de la ciudad extremeña muestran notables semejanzas con las intarsias florentinas. Los efectos de espacio de las intarsias italianas, cuyas trazas se deben frecuentemente a arquitectos, no se encuentran en las de Plasencia, limitadas en su mayor parte a la representación de la figura de un santo en un nicho muy sencillo. Sin embargo, los aspectos técnicos de las intarsias placentinas y florentinas son muy semejantes.

Proponemos, como ejemplo, la comparación de la intarsia con San Francisco de Asís de la sillería de Plasencia (fig. 2) y la que representa a San Eugenio en la sacristía de la catedral de Florencia (fig. 3). En ambos casos, los contornos de las figuras y el dibujo interior se han realizado con líneas oscuras. En las piezas de tela relativamente grandes, los efectos de luz y sombra en los pliegues de las vestiduras se consiguen mediante el uso de piezas con distintas tonalidades de color, que se unen de forma exacta para crear el efecto deseado. Además de no poseer el virtuosismo alcanzado por Giuliano da Maiano, las intarsias placentinas también se diferencian en la simplicidad del tratamiento de las manos y el rostro. El taller florentino ha utilizado en los rostros una multitud de pequeñas piezas, creando una representación con gran movimiento, difícil de distinguir en algunos casos de las igualmente dinámicas vestiduras. Por el contrario, la estructura de rostros y manos se ha conseguido en Plasencia con el uso exclusivo del dibujo grabado, realizado en piezas de madera relativamente grandes,

48 M. FERRETTI, op. cit., 1982, p. 495.

49 F.R. MAINIERI, "Legnaioli fiorentini e marchigiani a Perugia nel Quattrocento: gli armadi della Sacrestia di S. Pietro", Notizie da Palazzo Albani XVI, 2 (1987), pp. 51-56.

50 C. DIGIESI, op. cit., 1994, p. 85; y T. ROHARK, op. cit., 2007, p. 56.

51 M. FERRETTI, op. cit., 1982, p. 516. 


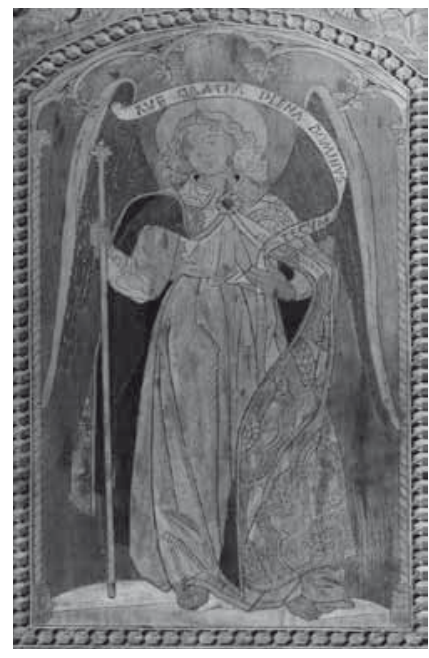

Fig. 4. Rodrigo Alemán, Sillería, detalle con Arcángel Gabriel, Catedral de Plasencia, 1497-1508. que se rellena de pasta o de piezas de madera oscura (fig. 4). De este modo se acentúa en las figuras placentinas el contraste entre la tranquilidad compositiva de los rostros y el dinamismo de los pliegues de las vestiduras. El dibujo ha facilitado además la decoración de las telas en Plasencia, insistiéndose en recrear telas de brocado y bordados valiosos, aspecto característico de estas representaciones.

La incrustación o grabado de elementos del dibujo en las piezas fue utilizado por algunos intarsiadores toscanos, por ejemplo Antonio di Neri Barili (1453-1516), cuya obra más importante fue la sillería de la capilla de San Juan Bautista en la catedral de Siena, construida entre 1482 y 1502 . Siete de los diecinueve tableros figurativos originales de esta sillería se conservan en la Colegiata de San Quirico d'Orcia, cercana a Siena ${ }^{52}$. Las representaciones comprenden algunas naturalezas muertas y figuras de santos, por ejemplo Santa Catalina, y profanas, entre las que citaremos a un músico tocando un laúd. Barili ha utilizado una amplia paleta de maderas con distintos colores naturales y estructuras, así como roble negro y maderas con distintos tonos verdosos. Además de la utilización del sombreado por pirograbado, ya descrito por Vasari, para conferir volumen a los pliegues y de la técnica de scagliola, mezcla de piezas de madera, serrín y mármol, en la representación de las ventanas y pilares, Barili se ha valido del pirograbado en la madera para modelar los cabellos y rostros de sus figuras, rellenando los surcos grabados con pasta negra, blanca o rojiza ${ }^{53}$.

Entre 1460 y 1463 se realizó, bajo la dirección de Giuliano da Maiano, una puerta intarsiada para la Abadía de Fiesole (fig. 5) que se conserva hoy en el Museo

52 La sillería de la catedral de Siena fue desmontada en 1661. Siete de los tableros dorsales fueron llevados a San Quirico d'Orcia en 1749. Otro tablero, con el autorretrato de Barili, se conservaba en el Museo de Artes Decorativas de Viena pero se perdió durante la II Guerra Mundial. T. ROHARK, op. cit., 2007, p. 251; y F. WINDISCH-GRAETZ, op. cit., 1983, pp. 20-21.

53 H. MICHAELSEN y R. BUCHHOLZ, op. cit., 2006, p. 53. 
de Artes Decorativas de Berlín ${ }^{54}$. Rodeadas por un friso ornamental, se ha representado en la parte superior de las hojas de la puerta la escena de la Anunciación, mientras la parte inferior está ocupada por grandes jarrones con flores. En las figuras se ha utilizado el relleno con pasta negra para dibujar los cabellos, los rostros y los pliegues de las vestiduras.

Otro ejemplo de la utilización de esta técnica de dibujo lo encontramos en la puerta que comunica las salas de los Ángeles y de la Audiencia del Palacio Ducal de Urbino ${ }^{55}$, atribuida, como todas las intarsias de Urbino, a talleres de escuela florentina $^{56}$. La decoración de esta puerta se ha dividido en seis campos, en los que aparecen representadas las artes liberales. Los contornos se han marcado no tanto por las diferencias cromáticas de las maderas sino por el dibujo, con marcado acento gráfico. Estas observaciones se pueden extender también a la puerta de las Virtudes en la Sala della Jole $e^{57}$. Las representaciones de las virtudes se han situado en una especie de nicho de fondo oscuro, como en Plasencia, realzándose así los contornos de las figuras.

La relación que vamos entreviendo entre las intarsias de Plasencia y las de la escuela florentina comprende no solo las características técnicas sino que se extiende también a la ornamentación utilizada. Como plenamente dentro de la tradición gótica tenemos que considerar los frisos que enmarcan las figuras de santos en Plasencia: cuajados de decoración vegetal a la que se incorporan pequeñas figuras humanas y animales, todo correspondiendo a motivos que se remontan al arte antiguo $^{58}$. Sin embargo, los respaldos de los sitiales altos han sido decorados con una ornamentación muy innovadora para la Castilla de la época. El repertorio de esta decoración rigurosamente simétrica va desde motivos puramente vegetales a motivos vegetales combinados con candelieri o con coronas vegetales, que rodean escudos de armas y están flanqueadas por angelillos.

El conjunto de la sillería placentina se completa con dos puertas intarsiadas, muy dañadas, que hoy están colocadas, de manera un tanto forzada, en los accesos al coro por los lados del evangelio y de la epístola ${ }^{59}$. Si no se observan con deta-

54 A.M. WILMERING, op. cit., 1999, p. 76; Kunstgewerbemuseum Berlin, Munich 1998, cat. 19; M. HAINES, op. cit., 1983, p. 164; y F. SCHOTTMÜLLER, "Sammlung der Bildwerke der christlichen Epoche. Arbeiten von Giuliano da Maiano”, Amtliche Berichte aus den Königlichen Kunstsammlungen, 39, 4 (1918), pp. 80-85.

55 Véase lám. 61 en H. FLADE, op. cit., 1986.

56 T. ROHARK, op. cit., 2007, p. 258; y P.L. BAGATIN, Le tarsie dello studiolo d'Urbino, Trieste, 1993, pp. 96-97.

57 Véase lám. 3-13 en O. RAGGIO, The Gubbio studiolo and its conservation. I. Federico da Montefeltro's palace at Gubbio and its studiolo, Nueva York, 1999.

${ }^{58}$ Citaremos, por ejemplo, el relieve con Apolo de la cripta de San Pedro en Roma. G. IRMSCHER, Kleine Kunstgeschichte des europäischen Ornaments seit der frühen Neuzeit (1400-1900), Darmstadt, 1984, p. 46.

59 Sobre la disposición original de las puertas, véase D. HEIM, op. cit., 2006, p. 84-85 y fig. 25. 


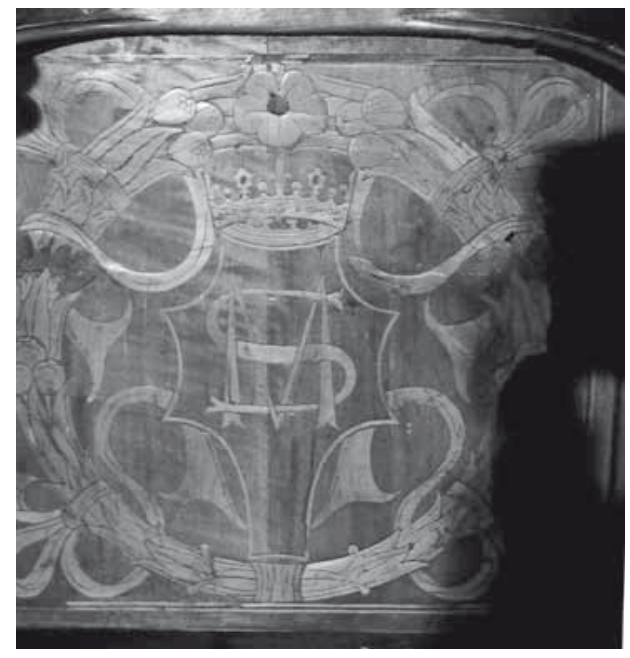

Fig. 6. Rodrigo Alemán, Sillería, detalle de respaldo alto con corona vegetal y escudo, Catedral de Plasencia, 1497-1508. 1le, las hojas de estas puertas, muy ennegrecidas, parecen simples tableros, por lo que no han recibido gran atención hasta ahora. Sin embargo, al iluminarlas con un foco de luz se reconoce fácilmente que cada hoja está dividida en cuatro campos con decoración en candelieri vegetal con motivos de bucráneos, cuernos y escudos de armas, todo ello intarsiado. Estos elementos aparecen enmarcados por un friso con decoración geométrica en mosaico a la que se enroscan ramas o sarmientos en espiral.

Muchos de estos motivos que encontramos en la ornamentación de las intarsias placentinas han sido también utilizados en obras similares de la Italia central, particularmente en Florencia. Un motivo con larga tradición es la corona vegetal que encontramos en los respaldos altos (fig. 6). Unos lazos aligeran la acusada geometría circular e imprimen un tono festivo. Un escudo de armas en el centro de la corona alberga las siglas SM en referencia a la advocación de la catedral, Santa María. Todos estos elementos se corresponden fielmente con los que presenta la corona de los paneles intarsiados del studiolo del Palacio de Gubbio (fig. 7), realizados entre 1478 y 1482 y también atribuidos al taller de Giuliano da Maiano ${ }^{60}$. Tanto los lazos como la forma del escudo, coronado por una diadema con una piedra preciosa, se encuentran también en Gubbio.

Otro conjunto de intarsias que nos parece interesante es el del armario de la sacristía de la Iglesia de San Pedro en Perugia (fig. 8), construido entre 1472 y 1474 por los intarsiadores toscanos Giusto di Francesco del Castello dell'Incisa y Giovanni di Filippo da Fiesole, quienes posiblemente trabajaban

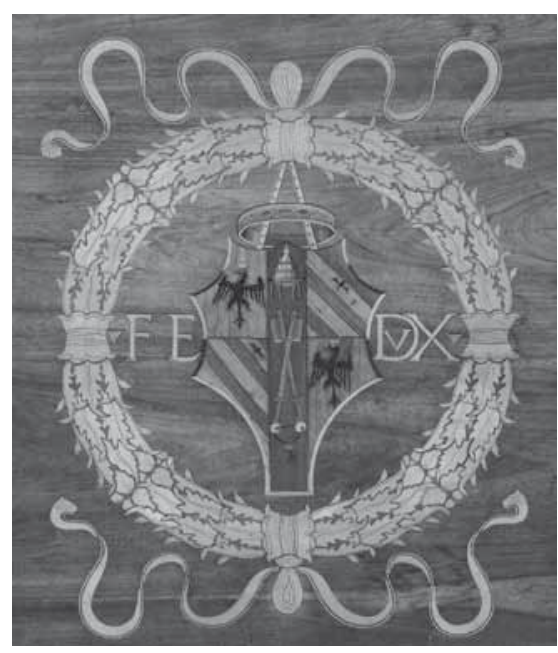

Fig. 7. Giuliano da Maiano (atribuída), escudo de Federico da Montefeltro, Estudiolo de Gubbio (extraído de Raggio 1999, lám. 5-16), 1478-1482.

${ }^{60}$ O. RAGGIO, "The Liberal Arts Studiolo from the Ducal Palace at Gubbio", The Metropolitan Museum of Art Bulletin, 53: 4 (1996), pp. 34-35; y A.M. WILMERING, op. cit., 1999, pp. 106-121. 
en el taller de Giuliano da Maiano ${ }^{61}$. Las puertas bajas de este armario han sido decoradas con ornamentos en los que, como en los respaldos de Plasencia (fig. 9), prevalecen los motivos vegetales con simetría central. Uno de los paneles de este armario presenta un jarrón con un ramo de flores, un motivo que relaciona Francesca Mainieri con la decoración de una pilastra de la Sala de los Ángeles del Palacio Ducal de Urbino $^{62}$. Aunque con un

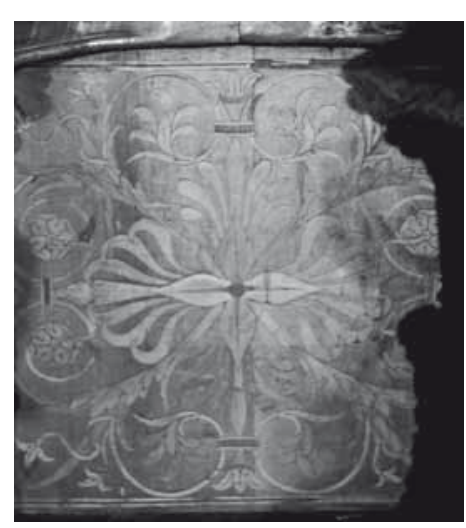

Fig. 9. Rodrigo Alemán, Sillería, detalle de respaldo alto con motivo vegetal con simetría central, Catedral de Plasencia, 1497-1508.

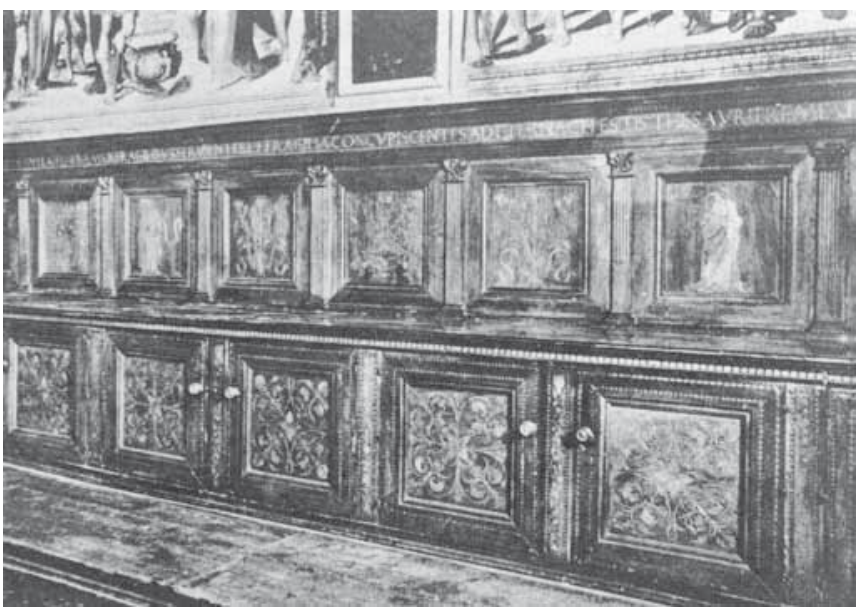

Fig. 8. Giusto di Francesco del Castello dell'Incisa y Giovanni di Filippo da Fiésole, armario de la Sacristía en San Pietro, Perugia, detalle, 14721474 (Foto: Bibliotheca Hertziana - Max Planck-Institut für Kunstgeschichte, Rom).

jarrón mucho más elaborado, ya hemos referido la presencia de este motivo en los respaldos de los sitiales altos de Plasencia. En ambos casos, las flores representadas son claveles.

En las intarsias de Plasencia aparece con frecuencia el motivo, ya usado en la Antigüedad, con ramas o sarmientos en espiral, combinado con jarras o con seres imaginarios. En el púlpito de Donatello, construido entre 1433 y 1438 originalmente para la catedral de Florencia, se observa en una de las consolas la decoración combinada del jarrón con flores y las ramas en espiral a los lados. De nuevo, es en el Palacio Ducal de Urbino donde podemos encontrar intarsias con tales motivos en la ya referida puerta con las artes liberales ${ }^{63}$. No hay que olvidar que se trata de motivos que, junto con aquellos en cande-

61 Mariotto da Pescaro colaboró en la construcción del armario. Parece que Giusto y Giovanni utilizaron en Perugia diseños anteriores del taller de da Maiano, por lo que se suponen que pertenecían al mismo. F. R. MAINIERI, op. cit., 1987, pp. 51 y 56-58.

${ }^{62}$ La decoración de pilastras se atribuye a Domenico Rosselli. F.R. MAINIERI, op. cit., 1987, p. 58.

63 Véase nota 55. 
lieri y las máscaras, alcanzaron una enorme popularidad en Florencia a partir de la década de $1460^{64}$.

No falta la decoración en candelieri en las intarsias placentinas. Constituye el eje central de la ornamentación de los respaldos de los sitiales de los reyes, flanqueada por ramas en espiral con abundancia de hojas silvestres. En vez de flores, las ramas sirven de soporte para seres imaginarios vegetales que disparan flechas, verdadera reliquia del canon tardogótico, tal como lo atestiguan los grabados de Israhel van Meckenem, por ejemplo, el que reproduce decoración en sarmiento con seres (B. 207) ${ }^{65}$. Por otro lado, la decoración que enmarca las figuras de los reyes presenta tallos verticales y centrales, que salen de jarrones, recordando motivos en candelieri. Partiendo de la corona situada en el centro de la parte inferior, esta decoración rodea totalmente el rectángulo donde se sitúa la figura real. Siguiendo la tradición medieval, los elementos vegetales acogen aquí y allá pequeños seres, como osos o angelitos. El interés de los artistas italianos por la decoración a candelieri aumentó considerablemente a partir de 1470. En el altar de la tumba de Santa Fina en Santa Maria Assunta en San Gimignano, obra de Benedetto da Maiano en 1475 , se ha introducido candelieri vegetal como decoración de las pilastras ${ }^{66}$. También fue un taller florentino el que realizó, a principios del siglo XVI, el revestimiento de madera de la sacristía de la iglesia de Santa Croce en Florencia, cuyas intarsias tienen pilastras con decoración a candelieri vegetal.

Otro interesante ejemplo de paralelismos lo encontramos en la comparación entre uno de los ornamentos de los respaldos de Plasencia y un friso que se encuentra sobre la puerta de la Sala del Trono del Palacio Ducal de Urbino. Realizado por Antonio da Milano después de 1476, representa una crátera coronada por un bucráneo y rodeada por cuernos de la abundancia, bajo los cuales hay tallos y ramas retorcidos ${ }^{67}$. En el respaldo placentino a que nos referimos, el bucráneo, motivo que también aparece en las puertas entre cuernos de abundancia, ha sido sustituido por una especie de cáliz con frutas.

Todos estos ejemplos y comparaciones ponen de manifiesto las relaciones entre la ornamentación de las intarsias de Plasencia y algunos motivos decorativos originarios de Florencia y ampliamente difundidos en Italia durante el último cuarto del Quattrocento. Es preciso recordar que las estampas con motivos ornamentales y trazados arquitectónicos fueron una de las vías primarias de expansión de determinados conceptos creativos. Una relación inequívoca con Florencia solamente podría establecerse si se pudiera determinar la presencia de motivos específicos de la región florentina que no fueran tema del arte gráfico en el momento de su

${ }^{64}$ G. IRMSCHER, op. cit., 1984, pp. 52-53, 150 y lámina 15.

65 F.W.H. HOLLSTEIN, German engravings, etchings and woodcuts 1400-1700. Israhel van Meckenem, vol. 24, Roosendaal, 1986, p. 249.

66 G. IRMSCHER, op. cit., 1984, p. 59 y lámina 22.

67 Sobre el ornamento en Urbino, véase G. IRMSCHER, op. cit., 1984, p. 56 y lámina 24b. 
incorporación en Plasencia. Es decir, buscamos motivos decorativos que también fueran relativamente nuevos en Florencia cuando se realizaron en Plasencia, pues esto supondría la práctica ausencia de un intermediario gráfico.

Ya en el Quattrocento apareció el grutesco moderno como elemento decorativo. $\mathrm{Su}$ historia comienza con el descubrimiento de la Domus Aurea, excavada a finales del siglo XV y totalmente desenterrada en $1506^{68}$. En el fresco representando el Nacimiento de la Virgen, obra de Domenico Ghirlandaio realizada entre 1486 y 1490 en la Iglesia de Santa Maria Novella de Florencia, se representan, como si fueran intarsias, los primeros grutescos ornamentales como tales ${ }^{69}$. Este detalle nos parece indicativo, en primer lugar, del valor que a las intarsias se concedía en el mundo artístico de la época y de la utilización en ellas de elementos ornamentales

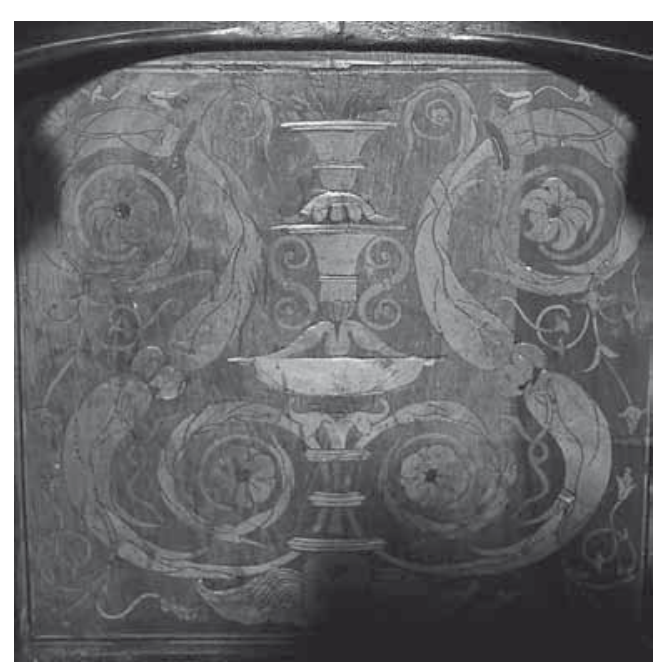

Fig. 10. Rodrigo Alemán, Sillería, detalle de respaldo alto con grutescos, Catedral de Plasencia, 1497-1508. pioneros, tal como eran por entonces los grutescos ${ }^{70}$. De nuevo son artistas florentinos los que introducen estas novedades.

Domenico del Tasso incorporó la decoración a candelieri en las intarsias de la sillería coral de la catedral de Perugia en $1487^{71}$ y en el revestimiento de la tribuna en la Sala de la Audiencia del Nobile Collegio del Cambio, realizado entre 1491 y $1493^{72}$. Tanto en las intarsias como en la decoración de talla de la tribuna, los grutescos se componen de elementos acentuadamente curvados, similares a los que se han utilizado en los respaldos de la sillería de Plasencia (fig. 10). Al comparar

68 No se sabe con certeza cuando se comenzaron estas excavaciones que se prolongaron durante décadas y que sacaron a la luz piezas que tuvieron una influencia decisiva en el desarrollo del arte en la época. G. IRMSCHER, op. cit., 1984, pp. 150-151.

69 Ibidem, p. 151.

70 Aparentemente las decoraciones murales romanas fueron utilizadas inmediatamente como inspiración de revestimientos parietales de la época, que en el siglo XV eran con frecuencia de paneles de madera.

${ }^{71}$ La sillería de Perugia fue iniciada en 1484 por el taller de Giuliano da Maiano y terminada en 1490 por Domenico del Tasso, montándose un año después. Un incendio destruyó un tercio de la sillería en 1985. C. DIGIESI, op. cit., 1994, p. 88; F. QUINTERIO, op. cit., 1996, pp. 418-422; y E. LUNGHI, Perugia. La cattedrale di S. Lorenzo, Perugia, 1994, pp. 47-48.

72 Véase lám. 35 y 36 en C. ACIDINI LUCHINAT, "Gli ornati delle tarsie perugine dal repertorio antiquario alla grottesca”, Annali della Fondazione di Studi di Storia dell'Arte Roberto Longhi, 1 (1984), pp. 58-59; y M.P. AGUILÓ, El mueble clásico español, Madrid, 1987, p. 114. Los tableros y las tribunas son atribuidas a Antonio da Mercatello, cuya firma aparece en una de las puertas. T. ROHARK, op. cit., 2007, p. 239. 


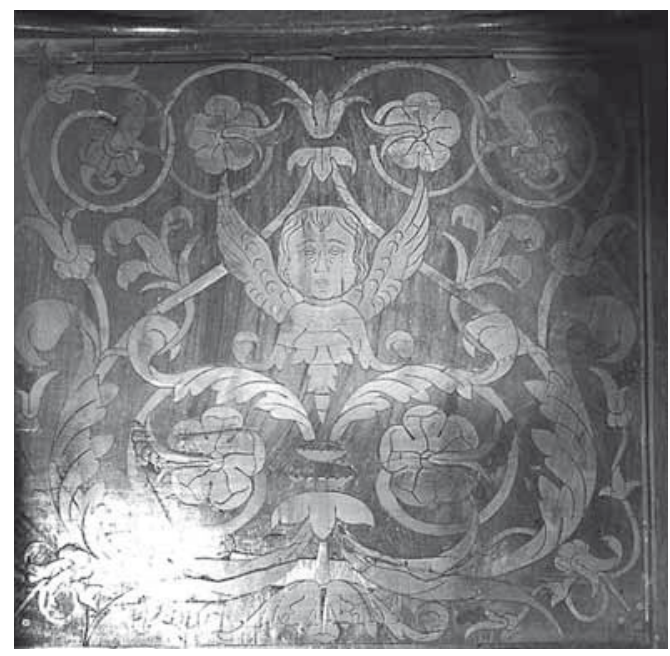

Fig. 11. Rodrigo Alemán, Sillería, detalle de respaldo alto con grutescos, Catedral de Plasencia, 1497-1508.

un tablero de la sillería de la catedral de Perugia con dos respaldos de la de Plasencia afloran nuevas semejanzas en estos trabajos separados menos de diez años en el tiempo (fig. 11). Los motivos usados en Plasencia no tienen la elegancia de los grutescos realizados por el taller florentino y tampoco es idéntica la combinación de elementos, lo que únicamente significa que no estamos ante obras del mismo taller. No obstante nos parece muy significativa la presencia en Plasencia de un motivo como el grutesco en una fase tan temprana.

La observación anterior se refuerza aún más si consideramos la decoración con grutescos del coro de Santa Maria Novella de Florencia, obra de Baccio d'Agnolo (1463-1543) entre 1485 y $1490^{73}$. Los motivos con jarrones y ramaje vegetal han sido aquí enriquecidos con máscaras, seres imaginarios, delfines y angelillos, de una manera que recuerda aquellos de las puertas y los respaldos de la sillería de Plasencia. Variando las combinaciones de elementos se generan ornamentaciones siempre distintas, una característica del grutesco moderno que evita las repeticiones en su uso en diferentes lugares ${ }^{74}$.

Mencionaremos, por último, los armarios de la sacristía de la catedral de Perugia (fig. 12), obra realizada entre 1494 y 1497 por Mariotto di Paolo Sensi da Gubbio, llamado Torzuolo. Por indicación del promotor del trabajo, estos armarios debían ser iguales a los de la Iglesia de San Pedro en la misma ciudad ${ }^{75}$. Sin embargo, tanto las proporciones como el programa iconográfico fueron modificados en la sacristía catedralicia. Entre las intarsias figurativas se ha colocado una serie de paneles, también intarsiados, con grutescos y

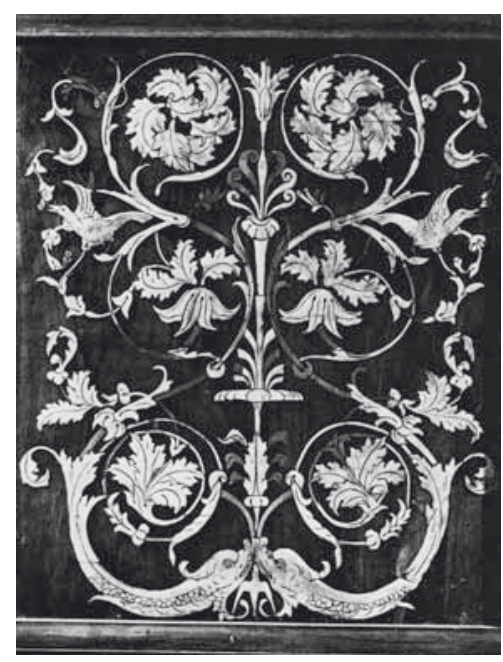

Fig. 12. Mariotto da Gubbio, Armarios de la sacristía, Catedral de Perugia, 1494-1497.

73 C. DIGIESI, op. cit., 1994, p. 89.

74 G. IRMSCHER, op. cit., 1984, p. 56.

75 C. ACIDINI LUCHINAT, op. cit., 1984, p. 59; F.R. MAINIERI, op. cit., 1987, p. 54; y E. LUNGHI, op. cit., 1994, p. 109. 
decoración floral. Como ocurre en Plasencia (fig. 11), estos grutescos de primera hora mantienen un acusado carácter vegetal.

La conclusión que extraemos de este conjunto de comparaciones es que el repertorio formal de la ornamentación de las intarsias de Plasencia se puede incluir dentro del correspondiente a la escuela de intarsiadores que, partiendo de Florencia, se extendió por Toscana, Umbría y las Marcas durante el último cuarto del siglo XV. La escasa diferencia temporal entre las intarsias placentinas, iniciadas en 1497, y las primeras incorporaciones de grutescos en la decoración italiana, que empiezan a aparecer poco antes de 1490, solo se justifica con una dependencia directa respecto al núcleo florentino. Es cierto que por estos años también se desarrollaba sobremanera la decoración con grutescos en Roma, sin embargo no existe en esta ciudad ninguna tradición de trabajo en intarsia. Las semejanzas, en la técnica y en los motivos utilizados, nos parecen tan acusadas y determinantes que nos permiten considerar las intarsias de Plasencia como la obra de un artista italiano familiarizado con lo que en Florencia y su entorno artístico, Umbría (Perugia) y las Marcas (Urbino), se hacía.

Los talleres más importantes de intarsiadores se dedicaban también a la exportación de muebles y otros artículos transportables. Está documentada la entrega por el taller de los Maiano de intarsias para una silla en Pisa, por cuya instalación se pagó en 1471 a Baccio Pontelli ${ }^{76}$. Se supone también que tanto el studiolo de Urbino como el armario de la catedral de Perugia fueron construidos en Floren$\mathrm{cia}^{77}$. Una posible importación de las intarsias de Plasencia desde Italia no se puede descartar a priori, considerando además que el trasiego de obras de arte entre Italia y España era intenso en esta época, habida cuenta la existencia de una aristocracia que no ahorraba en gastos para importar objetos artísticos italianos. Por ejemplo, Rodrigo de Vivar, hijo del cardenal Mendoza, encargó durante un viaje por Italia piezas para el Palacio de La Calahorra a un taller genovés. En este caso, el encargo era de tal complejidad y volumen que algunos entalladores italianos tuvieron que trasladarse a La Calahorra para trabajar in situ ${ }^{78}$.

La construcción de un mueble tan complicado como una sillería coral implicaba normalmente el trabajo del maestro del taller en la ciudad en que se iba a situar. Rodrigo Alemán compaginaba su presencia personal circunstancial con la permanente de miembros de su taller en Plasencia o Ciudad Rodrigo durante la construcción de las respectivas sillerías. Como ya hemos visto, las intarsias de Plasencia fueron realizas al mismo tiempo que los trabajos de talla. También hemos indicado que, aún incorporando numerosas características florentinas, las intarsias de Plasencia

${ }^{76}$ F. LICANDRO GRAZIOLI, "Contributo a Baccio Pontelli”, Antichità Viva, 5-6, 27 (1988), p. 43.

77 M. FERRETTI, op. cit., 1982, p. 488; y F.R. MAINIERI, op. cit., 1987, p. 53.

78 M.A. LEÓN COLOMA, "Un programa ornamental italiano: las portadas del palacio de la Calahorra (I)", Cuadernos de Arte de la Universidad de Granada, 29 (1995), p. 346. 
están lejos, en lo que se refiere al virtuosismo técnico, de lo que ejecutaban los talleres más importantes de la capital Toscana, que eran los que normalmente se elegían en el caso de importación de obras pues eran garantía de un trabajo bien ejecutado. Si no definitivas, éstas son dos razones para excluir la ejecución de las intarsias en Italia.

El principal argumento para suponer que las intarsias de Plasencia fueron realizadas en Castilla radica en las figuras que en ellas aparecen. Éstas tienen poco que ver con las composiciones figurativas, con frecuencia diseños de pintores famosos, que decoran estos trabajos en la Italia central ${ }^{79}$. No es un italiano el autor de los cartones que sirvieron como muestra para las intarsias, sino un pintor castellano que, a pesar de haber asumido en gran medida los elementos renacentistas, aún no ha renunciado totalmente a la tradición tardogótica tan arraigada en su tierra. Esto último es particularmente evidente en la elección de la postura y los gestos de las figuras, aún llenos de moderación, el detalle puesto en la descripción de las telas, de los brocados, de las vestiduras, todo lo cual encuentra sus raíces en la obra de Pedro Berruguete $^{80}$. Por tanto el trabajo en Plasencia parece más bien el de un intarsiador que está al tanto de las novedades que se han introducido en Florencia pero que sigue un camino propio en la elaboración de las mismas.

Todo apunta a que Berruguete fue también el inspirador de la obra, o al menos quien propuso decorar la sillería con intarsias. La labor de Berruguete en la corte de Federico da Montefeltro, donde participó en la ejecución de la serie de retratos de hombres ilustres para el studiolo del Palacio Ducal de Urbino, terminado en 1476 y cuya decoración incluía de forma preeminente tableros intarsia$\operatorname{dos}^{81}$, permitió al pintor palentino conocer el espléndido efecto creado por estos trabajos. Pero no solo el studiolo de Urbino se decoraba con intarsias, sino que también algunas puertas de salas importantes del palacio ducal se adornaban con filigranas y figuras intarsiadas, encargadas por el duque a talleres florentinos, las cuales encuentran paralelos en la técnica y en los motivos utilizados en Plasencia, como hemos visto. Gracias a su actividad en Urbino, disponía Berruguete de contactos, directos o indirectos, con talleres florentinos de intarsiadores, lo que podría animar al pintor a participar directamente en la realización de los tableros intarsiados placentinos ${ }^{82}$.

79 Véase nota 45. Relacionados con los talleres de Giuliano da Maiano y Baccio d'Agnolo son citados Sandro Botticelli, Filippino Lippi y Antonio Pollaiuolo como creadores de los diseños. M. HAINES, op. cit., 1983, pp. 136-138; y M. FERRETTI, op. cit., 1982, p. 521.

${ }^{80}$ Nos remitimos al artículo sobre los diseños de las intarsias de la sillería de Plasencia que con el título "Pedro Berruguete y las intarsias de la sillería coral de Plasencia" publicaremos en breve.

${ }^{81}$ No está claro si estas intarsias fueron obra del taller de Baccio y Piero Pontelli o del de Giuliano da Maiano. C. DIGIESI, op. cit., 1994, pp. 86-87; P.L. BAGATIN, op. cit., 1993, pp. 102-103; y A.M. WILMERING, op. cit., 1999, pp. 106-121.

82 Véase nota 80. 
Hacia el final del Quattrocento aparecieron en la Italia central los primeros síntomas de cambio en el gusto de los promotores, quienes empiezan a preferir los trabajos en talla a las costosas intarsias. Ante la decreciente demanda, muchos intarsiadores abandonaron esta técnica, de manera que en el siglo XVI pasó a ser trabajada tan solo por monjes ${ }^{83}$. Esta pérdida de interés pudo llevar a algunos intarsiadores a buscar nuevos encargos en otros países, en los que la popularidad de la intarsia iba en aumento. La muerte de Benedetto da Maiano en 1497 -su hermano Giuliano había muerto en 1490- representó sin duda un momento crítico para su taller, lo que obligaría a no pocos de sus colaboradores a reorientar su actividad ${ }^{84}$. En este ambiente de cierta decadencia, un encargo importante procedente de Castilla, transmitido por uno de los pintores de Montefeltro, seguramente encontraría el terreno abonado entre los intarsiadores italianos.

${ }^{83}$ F. WINDISCH-GRAETZ, op. cit., 1983.

${ }^{84}$ C. DIGIESI, op. cit., 1994, pp. 88 y 120. 